\title{
Function-centered rehabilitation increases work days in patients with nonacute nonspecific low back pain: 1-year results from a randomized controlled trial
}

Citation for published version (APA):

Kool, J. P., Bachmann, S., Oesch, P. R., Knuesel, O., Ambergen, T., de Bie, R. A., \& van den Brandt, P. A. (2007). Function-centered rehabilitation increases work days in patients with nonacute nonspecific low back pain: 1-year results from a randomized controlled trial. Archives of Physical Medicine and Rehabilitation, 88)(9), 1089-94. https://doi.org/10.1016/j.apmr.2007.05.022

Document status and date:

Published: 01/01/2007

DOI:

10.1016/j.apmr.2007.05.022

Document Version:

Publisher's PDF, also known as Version of record

Please check the document version of this publication:

- A submitted manuscript is the version of the article upon submission and before peer-review. There can be important differences between the submitted version and the official published version of record.

People interested in the research are advised to contact the author for the final version of the publication, or visit the DOI to the publisher's website.

- The final author version and the galley proof are versions of the publication after peer review.

- The final published version features the final layout of the paper including the volume, issue and page numbers.

Link to publication

\footnotetext{
General rights rights.

- You may freely distribute the URL identifying the publication in the public portal. please follow below link for the End User Agreement:

www.umlib.nl/taverne-license

Take down policy

If you believe that this document breaches copyright please contact us at:

repository@maastrichtuniversity.nl

providing details and we will investigate your claim.
}

Copyright and moral rights for the publications made accessible in the public portal are retained by the authors and/or other copyright owners and it is a condition of accessing publications that users recognise and abide by the legal requirements associated with these

- Users may download and print one copy of any publication from the public portal for the purpose of private study or research.

- You may not further distribute the material or use it for any profit-making activity or commercial gain

If the publication is distributed under the terms of Article 25fa of the Dutch Copyright Act, indicated by the "Taverne" license above, 


\title{
Function-Centered Rehabilitation Increases Work Days in Patients With Nonacute Nonspecific Low Back Pain: 1-Year Results From a Randomized Controlled Trial
}

\author{
Jan Kool, PhD, Stefan Bachmann, MD, Peter Oesch, MSc, Otto Knuesel, MD, Ton Ambergen, PhD, \\ Rob de Bie, PhD, Piet van den Brandt, PhD
}

ABSTRACT. Kool J, Bachmann S, Oesch P, Knuesel O, Ambergen T, de Bie R, van den Brandt P. Function-centered rehabilitation increases work days in patients with nonacute nonspecific low back pain: 1-year results from a randomized controlled trial. Arch Phys Med Rehabil 2007;88:1089-94.

Objective: To compare the effect of function-centered treatment (FCT) and pain-centered treatment (PCT) on the number of work days, permanent disability, and the unemployment rate.

Design: Randomized controlled trial.

Setting: Inpatient rehabilitation center.

Participants: Patients $(\mathrm{N}=174 ; 79 \%$ male; mean age, $42 \mathrm{y})$ with previous sick leave of 6 weeks or more.

Interventions: $\mathrm{FCT}(4 \mathrm{~h} / \mathrm{d}$ for $3 \mathrm{wk})$ emphasized activity despite pain by using work simulation, strength, endurance, and cardiovascular training. PCT $(2.5 \mathrm{~h} / \mathrm{d}$ for $3 \mathrm{wk})$ emphasized pain reduction and included passive and active mobilization, stretching, strength training, and a 4-hour mini back school with education and exercise. Analysis was by intention to treat.

Main Outcome Measures: Work days, return to work, rate of patients receiving financial compensation for permanent disability, and unemployment rate. Effect sizes (Cohen $d$ ) were defined as small $(0.2-0.5)$, moderate $(0.5-0.8)$, and large $(>0.8)$.

Results: After 1 year, the FCT group had significantly more work days (mean, 118; median, 39.5; interquartile range [IQR], 0-198) than the PCT group (mean, 74; median, 0; IQR, 0-160; Mann-Whitney $U$ test, $P=.011$ ). The odds ratio of returning to work in the FCT group relative to the PCT group was 2.1 (95\% confidence interval, 1.1-3.9). The differences in unemployment rates and in the numbers of patients receiving compensation for permanent disability were not significant.

Conclusions: FCT is more effective than PCT for increasing work days.

Key Words: Exercise therapy; Low back pain; Occupational diseases; Outcome assessment (health care); Randomized controlled trial; Rehabilitation; Sick leave; Vocational rehabilitation.

From the Department of Rheumatology, Rehabilitation Centre Valens, Valens, Switzerland (Kool, Bachmann, Oesch, Knuesel); and Departments of Methodology and Statistics (Ambergen) and Epidemiology (de Bie, van den Brandt), Maastricht University, Maastricht, the Netherlands.

Supported by the Swiss Federal Office of Health (grant no. 00.00437).

No commercial party having a direct financial interest in the results of the research supporting this article has or will confer a benefit upon the author(s) or upon any organization with which the author(s) is/are associated.

Reprint requests to Jan Kool, $\mathrm{PhD}$, School of Health Professions, Institute of Physiotherapy, Zürich University of Applied Sciences Winterthur, 8401 Winterthur,

Switzerland, e-mail: jan.kool@zhwin.ch.

0003-9993/07/8809-11561\$32.00/0

doi:10.1016/j.apmr.2007.05.022
(C) 2007 by the American Congress of Rehabilitation Medicine and the American Academy of Physical Medicine and Rehabilitation

$\mathbf{E}$ XERCISE, MULTIDISCIPLINARY rehabilitation, and functional restoration reduce sick days in patients with subacute and chronic low back pain (LBP) if compared with usual care. ${ }^{1,2}$ Choosing the most appropriate type of exercise and rehabilitation program is difficult. The results of most pragmatic trials comparing different treatments and methods of exercises are inconclusive. ${ }^{1,2}$ Rehabilitation programs that focus on pain reduction and include exercise are still widely used. Exercise of moderate intensity is supported by passive painmodulating treatments such as hot packs, electrotherapy, or massage. Activity and exercises that increase pain are avoided. In contrast, rehabilitation based on work hardening and graded activity programs encourages patients to continue their activities even if pain increases. ${ }^{2,3}$ It further remains unclear whether treatments shown to be effective in studies are also effective in populations with a different cultural background. In a metaanalysis ${ }^{4}$ evaluating the effect of exercise on sick leave in patients with nonacute LBP (duration $>6 \mathrm{wk}$ ), 8 of 14 studies excluded patients with insufficient knowledge of the national language. As a consequence, the validity of these results for populations with a different cultural background is limited.

The major costs of LBP are caused by work absenteeism and permanent disability. The total expenses of the Swiss Disability Insurance rose from SFr 4 billion in 1990 to SFr 11 billion in $2005 .^{5}$ Compared with 10 other European countries, Switzerland showed the highest rate of increase. ${ }^{6}$ Patients with health problems who are unlikely to return to their previous work are referred to the Swiss Disability Insurance, usually by their physician. The Swiss Disability Insurance uses work adaptation and professional training to keep persons at work. The possibilities for work adaptation are restricted because many patients have low education levels and very limited knowledge of the national language. In the third place, incentives for employers to prevent LBP-related disability and keep persons at work are insufficient. Patients with permanent disability receive a $100 \%$ disability allowance from the Swiss Disability Insurance if their work-related disability exceeds $70 \%$. In most cases, disability is less than $70 \%$, leading to a $25 \%, 50 \%$, or $75 \%$ disability allowance.

We conducted a pragmatic randomized controlled trial (RCT) in persons with nonacute nonspecific LBP. ${ }^{7}$ During a 3-week inpatient rehabilitation program, patients received either function-centered treatment (FCT) or pain-centered treatment (PCT). We analyzed work absenteeism, and the primary outcome was the number of work days in the follow-up year. The results after 3 months have been published previously. There was a significant benefit for the FCT group compared with the PCT group in the number of work days $(25.9 \mathrm{~d}$ vs $15.8 \mathrm{~d}$; effect size, .36; $P=.029)$. A follow-up duration of 3 
months is too short for conclusions about the effectiveness of an intervention aiming at improving work-related outcome. Consequently, 1-year results are presented that analyze whether the 3 months of benefit of the FCT group, compared with that of the PCT group, was maintained 1 year after the treatment.

This publication presents the results of work days, unemployment, and permanent disability during the follow-up year in patients with nonacute nonspecific LBP who received 3 weeks of either FCT or PCT.

\section{METHODS}

Methods and results regarding compliance and satisfaction have been more extensively described in the publication about the results after 3 months.

\section{Design}

We conducted an RCT. Between January 2000 and May 2003, we recruited and treated patients in the center for workrelated rehabilitation in Valens, Switzerland. Randomization was concealed and assessment of the primary outcome, work days, was blinded. Independent teams of therapists treated patients 6 days a week during 3 weeks. Patients could not be blinded to treatment, but they received no detailed information about the difference between the 2 treatments. The study was approved by the ethical committee of Canton St Gallen, Switzerland.

\section{Inclusion and Exclusion Criteria}

Eligible patients between 20 and 55 years of age with a primary diagnosis of nonacute (duration, $\geq 6 \mathrm{wk}$ ) nonspecific LBP and at least 6 weeks of sick leave in the previous 6 months were considered for participation in the study. Patients with a comorbidity interfering with treatment or working capacity were excluded. Patients with 2 or more positive predictive tests for non-return to work were excluded. ${ }^{7,8} \mathrm{We}$ included patients with different nationalities to evaluate the relative effectiveness of the treatments in subgroups with different cultural and psychosocial backgrounds.

\section{Treatment}

Function-centered treatment. The multidisciplinary team providing FCT consisted of a rheumatologist, a physical and occupational therapist trained in ergonomics, a sports therapist, a social worker, and a nurse. FCT was based on work hardening and functional restoration programs for 4 hours a day. The primary goal was to increase work-related capacity while emphasizing improving self-efficacy. The rheumatologist informed patients about the benign character of nonspecific LBP. Treatment was based on the patient's job demands; revealed in a work-related assessment; and consisted of work simulation, strength, and endurance training through isokinetic exercise, cardiovascular training performed by walking and aqua aerobics, sports therapy, and self-exercise. Patients were encouraged to continue their activities even if their pain increased. The work certificate after rehabilitation was based on the patient's work-related physical capacity and on medical findings.

Pain-centered treatment. The PCT team consisted of a rheumatologist, a physiotherapist, and a nurse, and the primary goal was pain reduction. The secondary goal was to decrease disability and improve return to work. The duration of treatment was 3 weeks and 2.5 hours a day. Physical therapy used individually selected mobilization, stretching, strength training, and a 4-hour mini back school with education and exercise.
Low-intensity movement therapy in the pool as well as progressive muscle relaxation using systematic contraction and relaxation of specific muscle groups further enhanced relaxation. Passive pain-modulating treatments such as hot packs, electrotherapy, or massage were used daily. In contrast to the FCT group, patients in the PCT group were told to stop activities when pain increased. After rehabilitation, the physician of the rehabilitation center determined the patients' working capacity. His work certificate was based on his medical findings.

In both groups, a rheumatologist prescribed medications such as analgesics and nonsteroidal anti-inflammatory drugs and might also apply local infiltrations in the musculature and other soft tissue of the lumbar region with 5 to $10 \mathrm{~mL}$ of $0.5 \%$ lidocaine and $40 \mathrm{mg}$ of triamcinolone. If required, a psychologist offered counseling. After rehabilitation, treatment and sickness certification were at the discretion of the patient's primary physician.

\section{Compliance and Satisfaction With Treatment}

We reported the evaluation of compliance and satisfaction with treatment in more detail in the study concerning results after 3 months. ${ }^{7}$ We monitored patients' compliance by recording attendance at scheduled appointments and length of stay. All patients expressed their satisfaction with treatment on a numeric rating scale from 0 (extremely dissatisfied) to 10 (completely satisfied). We also assessed the therapists' and physicians' compliance with FCT and PCT. A researcher audiotaped the verbal information the therapist or physician gave to patients on 25 consecutive occasions. Seven blinded experts independently rated the goals formulated, information about the treatment plan, explanation of the source of the complaints, and advice about coping with pain. Adequate adherence to the protocol was arbitrarily defined as an average overall score of more than 7.5 on a visual analog scale (VAS) from 0 (not at all according to the treatment protocol) to 10 (perfectly according to the treatment protocol).

\section{Outcome Measurement}

The primary outcome was the number of calendar work days in the follow-up year. Secondary outcomes were the rate of patients receiving unemployment benefits or permanent disability allowances. After 3 and 12 months, we sent questionnaires to the employer, known to be a valid source of information about sick leave. ${ }^{9}$ We also sent questionnaires to the patients' primary physician who determines fitness for work to increase data completeness. We compared the information from the employer and the physician to increase accuracy. The questionnaires assessed work absenteeism and adaptation of working hours per day. We accounted for time-reduced work. For example, a work day with $30 \%$ time reduction was counted as 0.7 work day. Information about disability allowances was obtained from the Swiss Disability Insurance. Depending on the level of disability, patients may receive a disability allowance of $25 \%, 50 \%, 75 \%$, or $100 \%$. Partial disability allowances were analyzed in the same manner as time-reduced work. Primary physicians, employers, and the Disability Insurance were blinded to the patients' group assignment because they were not informed in detail about the applied treatment during the 3 -week rehabilitation.

\section{Health Care Utilization}

We assessed the use of health care with questionnaires sent to the health insurance companies of the patients. 


\section{Statistics}

We performed a power calculation before the study started (power, .80; type I error, .05) indicating that 90 patients per group were needed to detect a difference of 40 workdays (standard deviation [SD], 95). We used SPSS ${ }^{\mathrm{a}}$ and $\mathrm{Stata}^{\mathrm{b}}$ for statistical analysis. Analysis was based on the intention-to-treat principle. $^{10}$

We compared the median number of work days during the follow-up year in the FCT and PCT groups with a MannWhitney $U$ test. Dispersion was determined by means of the interquartile range (IQR) representing the 25th and 75th percentile values. We determined effect sizes (Cohen $d$ ) defined as small $(0.2-0.5)$, moderate $(0.5-0.8)$, and large $(>0.8)$. We analyzed the influence of baseline differences and covariates on the number of work days in the 2 treatment groups. Covariates of interest were the duration of sick leave before treatment, age, cultural background, education, workload, and job qualification. Because a large proportion of patients in this study had zero work days during the follow-up year, we used negativebinomial logistic hurdle regression. ${ }^{11}$ This approach is particularly useful for the analysis of count data with an excess of zero counts. In a first step, logistic regression was used for analyzing the proportion of patients returning to work, defined as 1 or more days of work. Results are given as odds ratios (ORs) of returning to work in which the odds of returning to work for patients in the FCT group are compared with those of the PCT group.

In the second step of the analysis, the negative-binomial part of the model is used for analyzing the number of work days among those patients who have returned to work, defined as having worked during at least 1 day after treatment. The result parameter of the second step of the analysis is the incidence rate ratio (IRR). Here an incidence rate is proportional to the expected number of work days in a certain period conditional on having had at least 1 work day. The IRR is the quotient of 2 incidence rates. For example, the incidence rate for the FCT group is compared with the incidence rate for the PCT group.

We analyzed the effect of treatment and the influence of covariates on receiving a disability allowance with ordinal regression by using a proportional odds model with treatment as independent factor. We determined the ORs for unemployment after 1 year in the FCT compared with the PCT group. Logistic regression was used to evaluate the influence of treatment and covariates on the unemployment rate.

\section{RESULTS}

\section{Participants}

Figure 1 shows the participants of the study, and table 1 displays the baseline comparability of the 2 groups. Because recruitment rate was lower than expected, the duration of the study was prolonged for 4 months, and 174 instead of the initially planned 180 patients were included. There were no significant differences between the groups for most variables with the exception that more persons in the FCT group were involved in litigation.

\section{Protocol Compliance}

All patients attended at least $90 \%$ of the scheduled treatments, and treatment duration was comparable (table 2). Protocol compliance of therapists was above the predefined minimum level of 7.5 on a 10-point VAS in both treatment groups (see table 2). Side effects did not reduce compliance with the research protocol except in 1 patient in the FCT group who insisted on getting hot packs and massage for pain relief. All

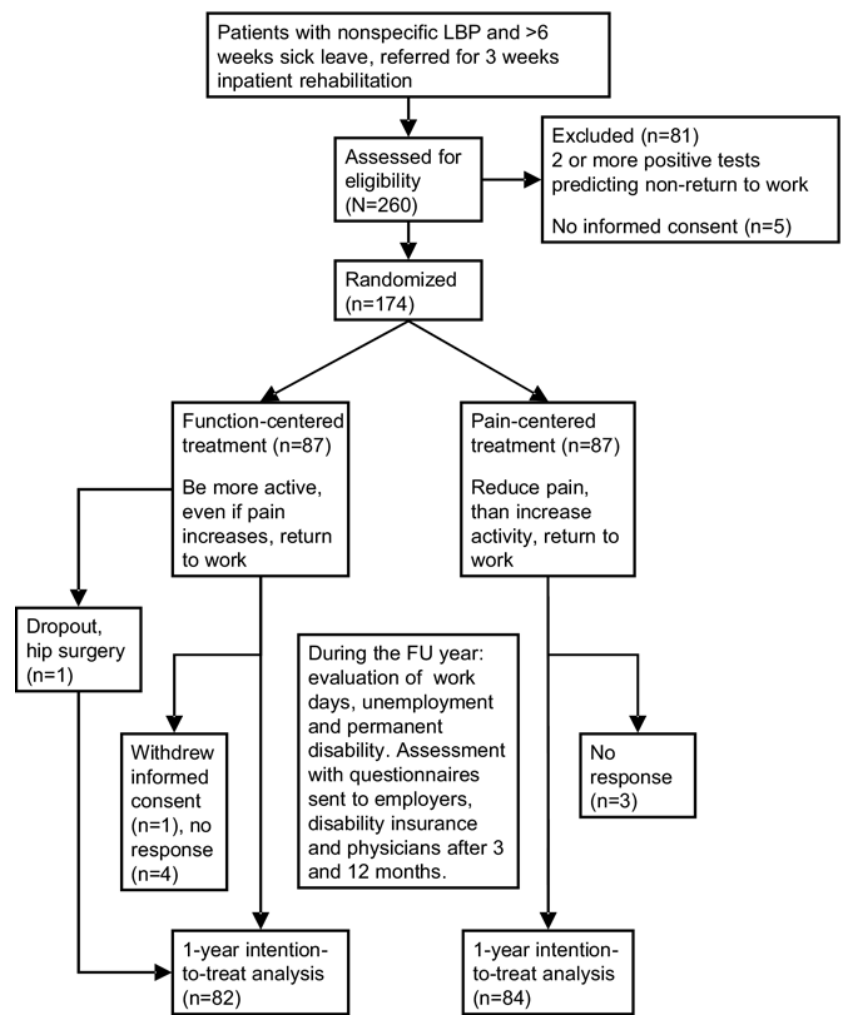

Fig 1. Flowchart of subjects through each stage of the study from initial screening to 1-year follow-up assessment. Abbreviation: FU, follow-up.

other patients were treated as intended. During rehabilitation, 1 patient was diagnosed with a necrosis of the femoral head and referred for surgery. Both patients were included in the analysis. Patients' satisfaction with treatment was the same in the FCT and PCT group, indicating that the effort to keep patients unaware of any expected treatment advantage was successful.

\section{Outcome Measurements}

Work days. We obtained completed questionnaires from $87 \%$ of the employers and $81 \%$ of the primary physicians. Differences in reporting between physicians and employers occurred in $12 \%$ of the cases. The research assistant contacted the involved persons and resolved these discrepancies. We retrieved the number of work days and the time restriction in the 1-year follow-up period for 82 of 87 (94\%) and 84 of 87 $(97 \%)$ of the patients in the FCT and PCT groups, respectively. The number of work days accounting for time-reduced work was significantly larger in the FCT group (mean $\pm \mathrm{SD}$, 118 1 134; median, 39.5; IQR, 0-198) compared with the PCT group (mean, 74 114 ; median, 0; IQR, 0-160; Mann-Whitney $U$ test, $P=.011$ ). The effect size was .35 , representing a small effect.

Negative-binomial logistic hurdle regression confirmed the effect of FCT compared with PCT. The first part of the analysis showed that the treatment effect was caused by a larger proportion of patients who returned to work in the FCT group $(59.8 \%)$ than in the PCT group $(41.4 \%)$. The OR of returning to work in the FCT group compared with the PCT group was 2.11 (95\% confidence interval [CI], $1.150-3.853 ; P=.016$ ). The second part of the negative-binomial logistic hurdle regression showed no difference in number of working days 
Table 1: Patient Characteristics Before Treatment

\begin{tabular}{|c|c|c|}
\hline Characteristics & $\mathrm{FCT}(\mathrm{n}=87)$ & PCT $(n=87)$ \\
\hline Mean age \pm SD $(y)$ & $41.6 \pm 8.4$ & $42.5 \pm 8.4$ \\
\hline Sex (men/women) & 69/18 & $68 / 19$ \\
\hline \multicolumn{3}{|l|}{ Diagnosis, n (\%) } \\
\hline $\begin{array}{l}\text { Low back and leg pain } \\
\text { (ICD-10 M 54.4) }\end{array}$ & $73(84)$ & $71(81)$ \\
\hline $\begin{array}{l}\text { Low back pain (ICD-10 M } \\
\text { 54.5) }\end{array}$ & $14(16)$ & $16(19)$ \\
\hline Pain medication, n (\%) & $67(77)$ & $62(71)$ \\
\hline Mean BMI \pm SD & $26.7 \pm 4.2$ & $27.2 \pm 4.0$ \\
\hline \multicolumn{3}{|l|}{ Marital status, n (\%) } \\
\hline Married & $63(72)$ & $67(77)$ \\
\hline Single & $13(15)$ & $10(11.5)$ \\
\hline Divorced & $11(13)$ & $10(11.5)$ \\
\hline \multicolumn{3}{|l|}{ Living arrangement, n (\%) } \\
\hline Alone & $15(17)$ & $16(18)$ \\
\hline With partner or family & $67(77)$ & $68(78)$ \\
\hline $\begin{array}{l}\text { Living alone, family lives in } \\
\text { original country }\end{array}$ & $5(6)$ & $3(3.5)$ \\
\hline Mean children \pm SD $(n)$ & $2.0 \pm 1.3$ & $2.0 \pm 1.4$ \\
\hline \multicolumn{3}{|l|}{ Citizenship status, n (\%) } \\
\hline Swiss citizen & $38(44)$ & $35(40)$ \\
\hline $\begin{array}{l}\text { Permanent immigrant } \\
\text { citizen }\end{array}$ & $40(46)$ & $42(48)$ \\
\hline $\begin{array}{l}\text { Permit depending on } \\
\text { employment }\end{array}$ & $8(9)$ & $9(10)$ \\
\hline Limited permit $(<1 \mathrm{y})$ & $1(1)$ & $1(1)$ \\
\hline \multicolumn{3}{|l|}{ Cultural background, n (\%) } \\
\hline Switzerland & $38(44)$ & $35(40)$ \\
\hline Southeast Europe & $31(35)$ & $39(45)$ \\
\hline Southwest Europe & $18(21)$ & $13(15)$ \\
\hline \multicolumn{3}{|l|}{ Education, $\mathrm{n}(\%)$} \\
\hline 6 years (primary school) & $11(13)$ & $14(16)$ \\
\hline $7-9$ years & $66(76)$ & $66(76)$ \\
\hline$>9$ years & $10(11)$ & $7(8)$ \\
\hline No professional education & $38(44)$ & $42(48)$ \\
\hline Unemployed, n (\%) & $18(21)$ & $20(23)$ \\
\hline \multicolumn{3}{|l|}{ Qualification at last job, n (\%) } \\
\hline Unskilled worker & $38(44)$ & $42(48)$ \\
\hline Skilled worker & $38(44)$ & $33(38)$ \\
\hline Foreman & $8(9)$ & $8(9)$ \\
\hline Independent worker & $3(3)$ & $4(4)$ \\
\hline Mean salary \pm SD (SFr) & $4501 \pm 1271$ & $4522 \pm 1248$ \\
\hline $\begin{array}{l}\text { Heavy work: workload }>10 \mathrm{~kg} \text {, } \\
\mathrm{n}(\%)\end{array}$ & $68(78)$ & $68(78)$ \\
\hline Mean work satisfaction \pm SD & $1.8 \pm 2.1$ & $2.4 \pm 2.9$ \\
\hline $\begin{array}{l}\text { Mean sick leave } 2 y \text { before } \\
\text { treatment } \pm \text { SD (calendar } \\
\text { days) }\end{array}$ & $184 \pm 156$ & $199 \pm 135$ \\
\hline Work-related litigation, ${ }^{*} \mathrm{n}(\%)$ & $16(18)$ & $9(10)$ \\
\hline
\end{tabular}

Abbreviations: BMI, body mass index; ICD, International Classification of Diseases.

*Mann-Whitney $U$ test, $P=.039$

between both groups among those patients who had at least 1 working day; the IRR was not significant (IRR $=1.10 ; 95 \% \mathrm{CI}$, $0.776-1.568 ; P=.586)$.

Because of baseline differences between the 2 treatment groups, litigation was entered into the model. In addition, we investigated the effect of the potential covariates sick leave before treatment, age, sex, education, job qualification, and cultural background. Including covariates into the model did
Table 2: Treatment Duration, Compliance, and Satisfaction (no significant differences)

\begin{tabular}{lcc}
\hline \multicolumn{1}{c}{ Variable } & FCT & PCT \\
\hline $\begin{array}{l}\text { Mean treatment duration } \pm \text { SD (d) } \\
\text { Protocol compliance therapists }\end{array}$ & $22.2 \pm 3.7$ & $22.3 \pm 3.8$ \\
$\quad$ (range, 0-10), median (IOR) & & \\
Treatment compliance patients & $8(5-8)$ & $7(5-8)$ \\
$\quad$ (range, 0-8), median (IOR) & & \\
Patient satisfaction (range, 1-7), & & \\
$\quad$ median (IOR) & $6.2(7.7-10)$ \\
$\quad$ Treatment & $6(4-7)$ & $6(4-7)$ \\
$\quad \begin{array}{l}\text { Explanations about complaints } \\
\text { Advice about coping with }\end{array}$ & $5(3-7)$ & $5(3-6)$ \\
$\quad$ complaints & $6(4-7)$ & $6(5-7)$ \\
Increased ability to control & $5(3-7)$ & $5(3-7)$ \\
$\quad$ complaints & &
\end{tabular}

not change the results. The logistic regression part of the model showed a significant positive effect of FCT compared with PCT. The OR of returning to work was 2.57 for patients in the FCT compared with the PCT group $(P=.011)$ (table 3$)$. There was a negative effect for litigation, longer sick leave before treatment, and southeast European cultural background in both groups. Education, workload, and job qualification were not associated with the number of working days. The negativebinomial regression part of the model showed that significantly

Table 3: The Effect of FCT and Covariates on Work Days During the Follow-Up Year Proportion of Patients Returning to Work (logistic regression)

\begin{tabular}{lccc}
\hline \multicolumn{1}{c}{ Variable } & OR & $95 \% \mathrm{Cl}$ & $P$ \\
\hline Treatment FCT vs PCT & 2.566 & $(1.242-5.301)$ & .011 \\
Litigation & 0.224 & $(0.068-0.737)$ & .014 \\
Previous sick leave (mo) & 0.910 & $(0.841-0.986)$ & .021 \\
Male & 0.858 & $(0.312-2.359)$ & .767 \\
Cultural background SE & 0.303 & $(0.125-0.734)$ & .008 \\
$\quad$ Europe/Switzerland & & & .219 \\
Cultural background SW & 0.513 & $(0.178-1.485)$ & \\
$\quad$ Europe/Switzerland & & & .746 \\
$\quad \begin{array}{l}\text { Age (y) } \\
\text { Education 6y/>6y }\end{array}$ & 0.993 & $(0.951-1.037)$ & .154 \\
Job qualification & 0.308 & $(0.061-1.555)$ & .071 \\
$\quad$ unskilled/other & 0.298 & $(0.080-1.110)$ & \\
\end{tabular}

No. of Work Days Among Those Patients Who Returned to Work (negative binomial regression)

\begin{tabular}{lccc}
\multicolumn{1}{c}{ Variable } & IRR & $95 \% \mathrm{Cl}$ & $P$ \\
\hline Treatment FCT vs PCT & 1.165 & $(0.819-1.657)$ & .396 \\
Litigation & 0.707 & $(0.318-1.568)$ & .393 \\
Previous sick leave (mo) & 0.962 & $(0.918-1.009)$ & .111 \\
Male & 1.361 & $(0.880-2.104)$ & .166 \\
Cultural background SE & 0.668 & $(0.419-1.062)$ & .088 \\
$\quad$ Europe/Switzerland & & & .734 \\
Cultural background SW & 0.909 & $(0.523-1.578)$ & \\
$\quad$ Europe/Switzerland & & & .654 \\
Age (y) & 1.005 & $(0.984-1.027)$ & .263 \\
Education 6y/>6y & 0.620 & $(0.268-1.433)$ & .570 \\
Job qualification & 1.168 & $(0.683-2.000)$ & \\
$\quad$ unskilled/other & & &
\end{tabular}

Abbreviations: OR, odds ratio of returning to work; SE, southeast; SW, southwest. 
more patients returned to work from the FCT group $(59.8 \%$ in the FCT, $41.4 \%$ in the PCT group). Among those patients who returned to work for 1 or more days, neither treatment nor any of the evaluated covariates were significantly associated with the number of working days (see table 3 ).

\section{Disability and Unemployment}

After 1 year, 32 of 87 patients in the FCT group and 38 of 87 patients in the PCT group received a permanent disability allowance, either full $(100 \%)$ or partial $(25 \%-75 \%)$. Ordinal regression showed that receiving a higher disability allowance was independent of treatment $(P=.199)$. Receiving a higher disability allowance was significantly associated with increasing age but not with litigation, sex, workload, education, job qualification, sick leave before treatment, and cultural background. Including these covariates did not change the results.

There was no difference in the unemployment rate after 1 year in the FCT and PCT group (FCT 37/87 [43\%] vs PCT 45/87 [52\%]; OR=.69; 95\% CI, 0.38-1.26; $P=.225) . \quad \mathrm{A}$ higher unemployment rate was generally observed in patients who were older $(P=.010)$, came from southeast Europe $(P=.002)$, or had a lower education level $(P=.026)$. Unemployment was independent of litigation, previous sick leave, sex, and job qualification. Logistic regression with unemployment as the dichotomous dependent variable, treatment as main effect, and correction for covariates did not change the results $(P=.245)$

\section{Health Care Use in the Follow-Up Period}

We assessed health care use in the follow-up period by means of a questionnaire sent to the health insurance provider. The return rate was $78 \%$. Interventions after rehabilitation were comparable in the FCT and PCT group. Diagnostic procedures, mainly radiography, magnetic resonance imaging, and computed tomography, were used in $44 \%$ and $39 \%$ of the patients, respectively. Medications, mainly analgesics and antidepressants, were used by $90 \%$ and $94 \%$ of the patients. Physical and occupational therapy was prescribed to $83 \%$ and $78 \%$ of the patients.

\section{DISCUSSION}

This is the first study in Switzerland showing a significant increase in the mean number of work days during the follow-up year after FCT compared with PCT (118d vs 74d, effect size, $.35)$.

The results show that the effect during the first 3 months was maintained until 1 year after treatment. Although the formal effect size statistic only indicates a small effect, gaining over 40 days of additional work can be considered a substantial improvement given the large cost per lost work day. Work days during the follow-up year in both treatment groups were negatively influenced by litigation, longer sick leave before treatment, and southeast European cultural background without an interaction with treatment. There was no significant effect of treatment on the unemployment rate or on the number of patients receiving a permanent disability allowance.

Strengths of this study were the relatively large number of patients, applicability of the treatment to patients with other cultural backgrounds, and limited knowledge of the Swiss national language. The population under study was representative for the population in Switzerland at risk to develop permanent LBP disability. The studied group was characterized by a long duration of LBP and sick leave and a large proportion of predominantly male workers with a low education level. We did not exclude patients with minimal knowledge of the Ger- man or Italian language. The results of this study are important because a recent meta-analysis concluded that it remained unclear whether exercise reduces work absenteeism. ${ }^{12}$ Compared with a study in Sweden by Lindström et al, ${ }^{3}$ our study included fewer patients with other nationalities (58\% vs $75 \%$ ). In our study, the off-work duration was longer and pain intensity was higher (5.6 points vs 3.3 points, on a 10 -point scale). Our results are in accordance with other research indicating that exercise is safe and reduces disability. ${ }^{13}$

\section{Study Limitations}

Limitations of our study are that we did not use a workplace intervention, which might have improved the results. We did not assess psychologic comorbidity and several other factors that potentially influenced the outcome. Randomization as used in this study remains essential to generate comparable groups regarding known and unknown predictive factors. The rehabilitation team of the FCT group also included a social worker. Part of the difference in outcome could be caused by this factor. There was no difference between groups in the use of psychologic counseling. Less than $10 \%$ of the patients in both groups were referred and received on average two 30-minute sessions.

Blinding was not possible in patients and in the members of the multidisciplinary teams. The best available alternative was to keep patients unaware of the treatment of the other group and of any expected treatment advantage. The excellent treatment compliance in both groups and the comparable patient satisfaction indicate that this attempt was probably successful.

The effect of the FCT on the number of disability allowances and the unemployment rate after 1 year was not significant. This is in accordance with the 3 months of results and with the results of a previous meta-analysis. ${ }^{4}$ Insufficient power may be an important reason for the nonsignificant difference in the unemployment rate and in the number of patients receiving a disability allowance. The power of this study to detect a $20 \%$ reduction in disability allowances is only .19 corresponding with a type II error probability of $81 \%$. Accounting for each day of work absence with $€ 155$ (U.S. $\$ 213^{14}$ ), the savings during the follow-up year are €6200 (U.S. \$8520). The cost of rehabilitation paid by health insurance is $€ 220$ (U.S. \$303) per day or $€ 4900$ (U.S. \$6749) per patient in the FCT and PCT groups.

The unemployment rate after 1 year was high in both groups. The duration of unemployment benefits is limited to 2 years. After this period, patients may either receive a disability allowance or social benefits. The difference in the proportion of patients at work between groups was maintained until 1 year after treatment. Therefore, we plan a 3-year follow-up and cost-effectiveness analysis.

Further research is needed to identify the essential elements of treatment based on risk-factor assessment during the acute phase of LBP. ${ }^{15}$ Outpatient programs that may be more costeffective must be developed. In view of the fact that the majority of patients in this study did not return to work, a further reduction of work-related disability is urgently needed. Improvements in outcome may be reached by earlier interventions and by combining rehabilitation and workplace interventions. In addition, politicians and insurance companies in Switzerland should establish legal and financial incentives for workers, employers, and involved insurances to reduce longterm work-related disability. These incentives are nearly nonexistent in Switzerland. 


\section{CONCLUSIONS}

Compared with PCT, FCT significantly increased the average number of work days during the follow-up year. The benefit was 40 days, and the effect size was .35 . In both treatment groups, work days were negatively influenced by litigation, longer sick leave before treatment, and southeast European cultural background. Treatment had no effect on the unemployment rate or the number of patients receiving a permanent disability allowance, but this result must be interpreted with caution because the study was underpowered for this outcome.

Acknowledgment: The study enrolled subjects before 2005 and hence was not registered in a trial registry.

\section{References}

1. Guzman J, Esmail R, Karjalainen K, Malmivaara A, Irvin E, Bombardier C. Multidisciplinary rehabilitation for chronic low back pain: systematic review. BMJ 2001;322:1511-6.

2. Schonstein E, Kenny DT, Keating J, Koes BW. Work conditioning, work hardening and functional restoration for workers with back and neck pain. Cochrane Database Syst Rev 2003;(1): CD001822.

3. Lindström I, Öhlund C, Eek C, et al. The effect of graded activity on patients with subacute low back pain: a randomized prospective clinical study with an operant-conditioning behavioral approach. Phys Ther 1992;72:279-90; discussion 291-3.

4. Kool J, de Bie R, Oesch P, Knusel O, van den Brandt P, Bachmann S. Exercise reduces sick leave in patients with non-acute non-specific low back pain: a meta-analysis. J Rehabil Med 2004; 36:49-62.

5. Buri M. Disability Insurance Statistics. Berne: Swiss Federal Social Insurance Office; 2005.

6. Marin B, Prinz C. Facts and figures on disability welfare. A pictographic portrait of an OECD report. Vienna: European Centre of the OECD; 2003.
7. Kool J, Oesch P, Bachmann S, et al. Increasing days at work using function-centered rehabilitation in nonacute nonspecific low back pain: a randomized controlled trial. Arch Phys Med Rehabil 2005;86:857-64

8. Kool J, Oesch P, Bachmann S. [The predictive validity of nationality for functional capacity and treatment outcome] [German]. Schweiz Arzteztg 2000;81:2656-69.

9. van Poppel MN, de Vet HC, Koes BW, Smid T, Bouter LM. Measuring sick leave: a comparison of self-reported data on sick leave and data from company records. Occup Med (Lond) 2002; 52:485-90

10. Hollis $\mathrm{S}$, Campbell $\mathrm{F}$. What is meant by intention to treat analysis? Survey of published randomised controlled trials. BMJ 1999;319: 670-4.

11. Gurmu S. Semi-parametric estimation of hurdle regression models with an application to Medicaid utilization. J Appl Econ 1997;12: 225-42.

12. Hayden JA, van Tulder MW, Malmivaara AV, Koes BW. Metaanalysis: exercise therapy for nonspecific low back pain. Ann Intern Med 2005;14:765-75.

13. Rainville J, Hartigan C, Martinez E, Limke J, Jouve C, Finno M. Exercise as a treatment for chronic low back pain. Spine J 2004; 4:106-15.

14. Knuti R, Schwaniger U. Arbeit und Gesundheit. In: Kocher G, Oggier W, editors. Gesundheitswesen Schweiz 2004-2006. Solothurn: KSK; 2001. p 27-33.

15. Grotle M, Vollestad NK, Brox JI. Screening for yellow flags in first-time acute low back pain: reliability and validity of a Norwegian version of the Acute Low Back Pain Screening Questionnaire. Clin J Pain 2006;22:458-67.

\section{Suppliers}

a. Version 13; SPSS Inc, 233 S Wacker Dr, 11th Fl, Chicago, IL 60606.

b. Version 9; StataCorp, 4905 Lakeway Dr, College Station, TX 77845 . 